To be fair, the editors acknowledge these omissions and others in the preface.

Two chapters deserve a special mention: that on dealing with spiritual matters, and the epilogue 'The physician as a comforter'. I think these chapters reflect that the book has been written for practitioners at the 'coalface', who are asked regularly about issues associated with dying, about the veracity of belief systems, be they religious or otherwise, and may have their own belief systems challenged by this work. Here, the book departs from being a manual, but perhaps fittingly so, since it reminds clinicians that however expert their knowledge, medical management and monitoring, their care is incomplete without consideration and respect for their patients' feelings and beliefs.

Gill Garden Consultant in Psychological Medicine, Pilgrim Hospital, Boston PE2I 9QS, UK. E-mail: Gillian.Garden@ulh.nhs.uk

\section{Textbook of Psychosomatic Medicine}

Edited by James L. Levenson. Washington, DC: American Psychiatric Publishing. 2005. 1120 pp. US $\$ 169.00$ (hb). ISBN I585621277

Isn't psychosomatic medicine meant to be defunct, an obsolete term abandoned in the wake of unproven aetiological theories of medical illness? Hasn't it been superseded by the more practical and evidence-based subspecialty of liaison psychiatry, or consultation-liaison psychiatry as some prefer to call it? The speculative formulations of Alexander and Dunbar have indeed been discarded but psychosomatic medicine has enjoyed a recent resurrection, courtesy of the American Board of Medical Specialties. In 2001 the American Academy of Psychosomatic Medicine applied successfully to the American Board of Psychiatry and Neurology for psychosomatic medicine to be recognised as a subspecialty of psychiatry. Formal approval was subsequently obtained from the required professional bodies and the first certifying examinations are due to be held in the summer of 2005 . Quite why 'psychosomatic medicine' was chosen as the term to define the subspecialty is not clear, given its association with dubious historical baggage. However, when one looks at the scope of the subject, and the content of this book, the range of problems is immediately familiar. The editor has adopted the definition of psychosomatic medicine as the area of psychiatry where practitioners have particular expertise in the diagnosis and treatment of psychiatric disorders and difficulties in medically ill patients. Three groups of clinical problems are said to fall within its remit: comorbid psychiatric and general medical illnesses complicating each other's management; somatoform and functional disorders; and psychiatric disorders that are a direct consequence of a medical condition or its treatment. In other words, this is what most of us in the UK still call 'liaison psychiatry'.

New examinations are a gift to academic publishers. In the light of American Board recognition it is not surprising that

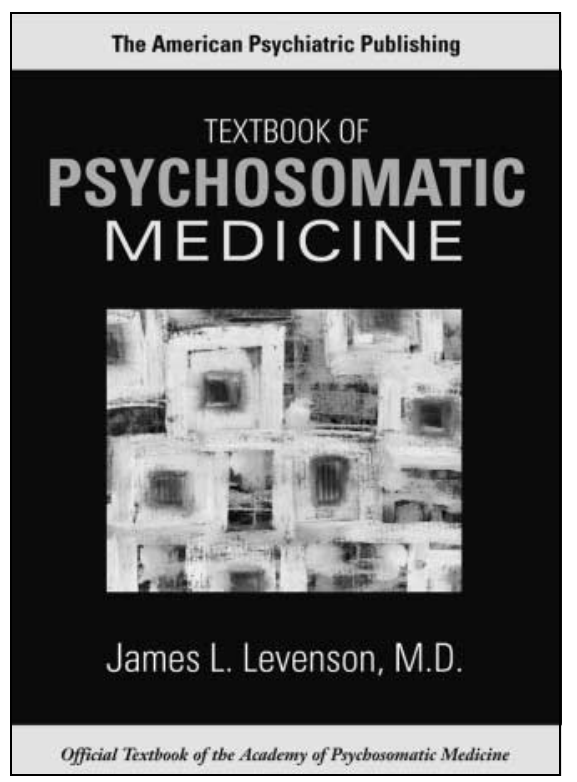

some large textbooks have been published recently and these will undoubtedly become required reading for examination candidates. This is the third substantial book in the field to appear since the millennium. It is a book on the grand scale and James Levenson has achieved a considerable success in bringing it to fruition. This has been a Herculean task, supported by an editorial board which has a multinational membership, with the intention of providing a broadly based perspective.

The book has a conventional format, being organised into four parts which cover general principles, clinical symptoms, medical specialties and treatment. By far the largest part is taken up with a review of psychiatric disorders in various medical specialties such as gastroenterology, oncology, cardiology, neurology and paediatrics. The standard is consistently high. The text is accompanied by many helpful tables and there is an emphasis on practical advice about how to manage difficult clinical problems. Particularly interesting are the chapters on ethical and legal issues. Liaison psychiatrists are becoming increasingly involved in helping resolve ethical dilemmas in clinical practice and in assessing a patient's capacity to refuse or consent to medical treatment. The problems discussed in these chapters will be universally familiar to clinicians, but statutory and case law will vary considerably from one country to another.

This is a book for the specialist in liaison psychiatry or, as the editor would prefer, psychosomatic medicine. It is therefore likely to have limited appeal, but it will be an invaluable source of information for psychiatrists and psychologists whose work brings them into frequent contact with general hospital patients. Outside the USA it will probably be a book for the institutional library rather than the personal bookshelf.

Geoffrey Lloyd Visiting Consultant Psychiatrist, Priory Hospital North London, London NI4 6RA, UK. E-mail: g.glloyd@btinternet.com 